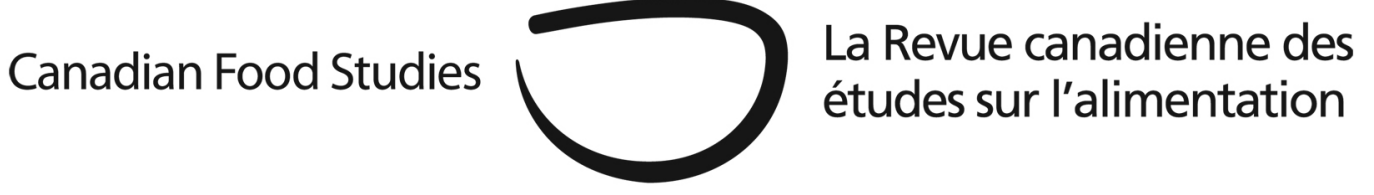

\title{
Perspective
}

\section{Notes from the Nanaimo bar trail}

\author{
Lenore Lauri Newman
}

Department of Geography, University of the Fraser Valley, Abbotsford, BC, lenore.newman@ufv.ca

\begin{abstract}
Archival work suggests that the Nanaimo bar is based on a recipe for unbaked chocolate cake published in the Vancouver Sun in 1947 and republished in 1948. The bar itself was likely developed by a member or members of the Nanaimo Hospital Auxiliary, and the first known recipe was published in 1952 in that group's cookbook. The mystery of the bar's origins is explored, the bar's place within the tradition of 'dainties' is noted, and its current role within Nanaimo’s efforts at place making is documented.
\end{abstract}

\section{Introduction}

There is an enjoyable puzzle to food. Even the most quotidian element of a cuisine or foodway hides a convoluted and often deeply personal tale of adaptation, evolution, and affection. The origin of the Nanaimo bar is an enduring local mystery that has piqued interest in the confection locally and nationally. (See Zeidler [2013] for a recent summary of the origin mystery.) The story of food is often unsung, hidden in cookbooks, newspapers, and oral histories. Study of these tidbits can reveal a surprisingly complex culinary tradition; as noted by Gertz (1993, p.19) "one must find cultural artifacts capable of rendering the curve of social discourse into an inspectable form.” As Adema (2009) notes, food is encoded with significance and is a vehicle for communication. The Nanaimo bar speaks of a land and its people, and the bar continues to act as a place-making cultural artifact.

The Nanaimo bar is a three-layer dessert, with a bottom layer of unbaked chocolate cake, a filling of custard-flavoured butter icing, and then a final layer of dark chocolate. It is calorie heavy, combining butter and sugar with as many as five branded products: Graham crackers, 
Bird's custard powder, Baker's chocolate, Fry's cocoa, and Tropic coconut. It is one of the best known recipes that can truly be said to be Canadian, and is one of a handful of really well known Canadian dishes (Hashimoto \& Telfer, 2006), yet it seems an odd ambassador for a people who Hlutchy (2003) notes are more usually associated with fresh, local, and wild foods. Voted the nation's favourite confection in a 2006 survey in the National Post (2006), the bar is made in homes and sold commercially across the country. But what is Canadian about this cookie? How does it fit within our cuisine? The bar's namesake, Nanaimo, British Columbia, is not otherwise known as a centre for culinary innovation. It is a resource industry town on the East Coast of Vancouver Island that began as a coal-mining hub, and by the mid1950s the town's economy was dominated by the pulp and paper industry, creating a solid bluecollar middle class.

The idea of Canadian food or Canadian cuisine is an ethereal concept, a loose web of regional elements following themes that vary strongly between urban and rural, East and West. Canada's cuisine has been described as shaped by regions, climate, and cultural groups (Duncan, 2003), and as incorporating native ingredients, regional flavours, and multicultural elements (Jacobs, 2009).

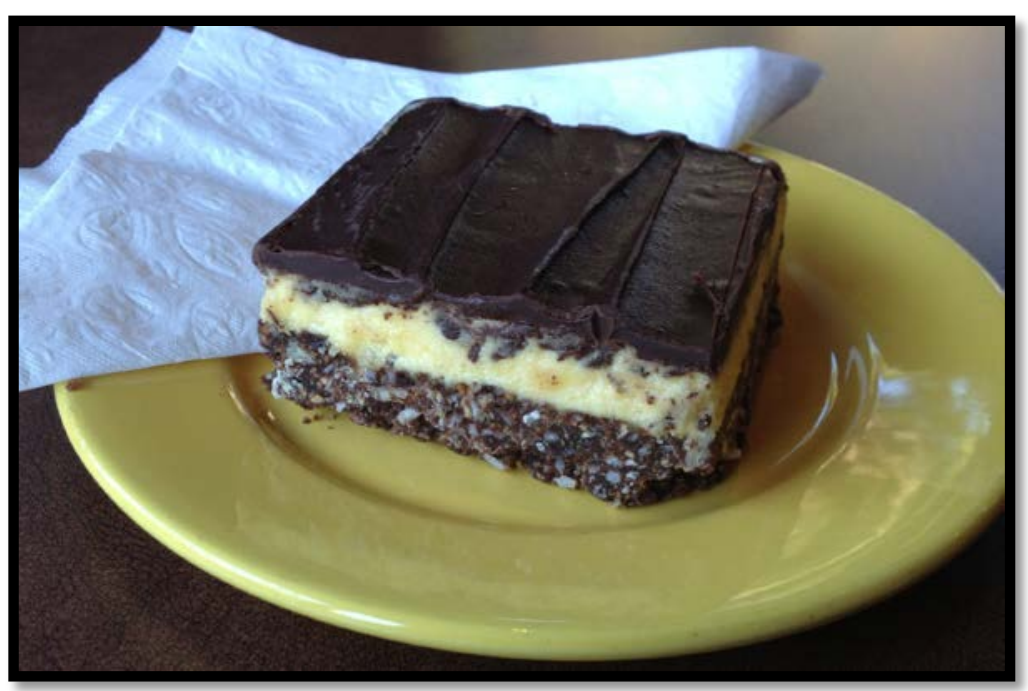

Figure 1: A classic Nanaimo bar Elsewhere (Newman, 2012) Canadian cuisine has been described as seasonal. A Nanaimo bar is none of these things; it is what Johnson and Baumann call a 'norm breaking' food (2010). Why is it a Canadian icon? Margaret Fraser provides what is perhaps the best answer: the Nanaimo bar is Canadian because "we know, at some point, someone from Canada came up with it” (Tucker 2011, p.1). Hashimoto and Telfer (2006) go as far as to call the bar famous, but say nothing as to how the bar developed; they do caution that foods are invested and reinvested with meaning and often with vehement local patriotism. Together with Shea Wind, an archival student at University of the Fraser Valley, I headed out to better understand the bar, and perhaps sort out the mystery of its origins. Our methodology involved web and literature searches, a search of all period cookbooks in the region and a targeted national search focusing on the 1940s and 1950s, and an archival search of the Vancouver Sun newspaper stretching from 1930 to 1960. Targeted interviews of individuals highlighted in earlier search efforts were also conducted, and the minutes of several women's auxiliary groups were explored.

\section{The no-bake dessert in history}

The Nanaimo bar sits within a long tradition of no-bake deserts. Using up stale baked goods in new dishes traces back to antiquity; Apicius describes a Salacattabia (jelly) made with bread crumbs soaked in a wine mixture, mixed with cheese, and chilled in a mold packed in snow 
(Vehling, 1977). Saberi (2002) has explored the modern evolution of this dish from trifles to icebox cakes. English trifle, which uses stale sponge cake brushed with liquor, a layer of custard, a layer of jam, and cream on top, continues this tradition, and dates back to at least the late 16th century. The trifle begat the charlotte, which can be found in a great number of recipes right into the 1930s; almost every book we examined had several. From charlottes we get the icebox or refrigerator cake, and during the research for this project we noted a transition from the overwhelming use of ladyfingers as a cake base to other variations including the crushed or whole Graham cracker. Quick refrigerator squares became extremely popular after World War II, when butter and sugar was once more available. By 1950, Graham rolls and Graham marshmallow squares appeared in almost every book we studied. Of the four dozen books examined, all of the books appearing post 1950 contained recipes that combined marshmallows, sweetened condensed milk, and crumbled cookies to create a tooth-achingly sweet goo.

\section{The origin of the Nanaimo bar}

If the origin of the Nanaimo bar could be discovered at all, it was likely to be found in a newspaper or community cookbook. The problem, however, is that many of the small church cookbooks stayed in private hands, making them hard to find (Kowalchuk, 2013). Elizabeth Driver (2009) noted how similar the books are to each other; recipes were copied word for word, submitted to new newspapers or books, and transmitted to new regions. The Nanaimo museum's collection of recipes confirmed that the name of the bar came after the recipe itself. The first known recipe was included in the 1952 Women's Auxiliary to the Nanaimo Hospital Cookbook, which has three nearly identical recipes for the dessert that differ only slightly from the modern version, under the names Chocolate Square (twice) and Chocolate Slice; the one closest to the modern bar was submitted by Mrs. E. MacDougall.

Aside from this, the internet and gray literature search turned up a great number of rumours, but no verifiable origin. Determining the exact origin of a food item is difficult; in the place of documentation, one often finds what Andrew Smith calls fakelore (2001). Food creates strong memories, and can often create a fictional past (Holtzman, 2006). Smith (2001) points to particularly robust fakelore that occurs in cases where stories sound true, address a mystery, or are objects of local boosterism. As he notes, "much of what has been written under the rubric 'culinary history' has been collections of twice-told myths” (p. 259). The internet, and in particular sites such as Wikipedia, haven't helped matters. In the case of the Nanaimo bar, an origin in the Ladysmith and Cowichan Women's Institute Cookbook was repeated widely online, but not only has the book never been found, there is no evidence that such an organization even existed. Organizations leave traces; the Nanaimo Hospital auxiliary minutes are archived, so it is known in that case that the organization did exist.

A more promising lead remained from earlier searches. In the mid-1980s the Nanaimo Chamber of Commerce attempted to determine the bar's origin, and noted that Phyliss Millgan, a member of the Nanaimo Hospital auxiliary, reported that the recipe first appeared in their cookbook and was based on a recipe for a Chocolate Fridge Cake from the Vancouver Sun (Rayburn, 2001). Though the cookbook exists, and is believed to be the earliest book containing the recipe, the recipe in the Vancouver Sun was not found. This gave reason for a targeted search of the recipes presented in the Sun between 1930 and 1960, which were published as part of a daily contest held under the Edith Adams brand name. Edith Adams, like Betty Crocker, was a 
gestalt identity created by the Vancouver Sun in 1924 to offer recipes and advice to the homemaker. An excellent description of Edith's interesting history is given in Driver (2005).

The first known printed use of the term Nanaimo bar remains the one identified in the Vancouver Sun. On April 11, 1953, the recipe appears in the Vancouver Sun as the London Fog Bar (Vancouver Sun, 1953), submitted by Mrs. David Orr. Edith Adams notes that they are also called Nanaimo bars. (This was also noted on the CakeSpy blog during the blog author's 2011 search for the origin.) It wasn't possible to determine how the Edith Adams column determined the alternate name, but it is imaginable that the recipe had been submitted, under different names, by multiple contestants. The recipe is identical to the one in the Nanaimo Hospital auxiliary cookbook. The recipe then appeared later that year, only as Nanaimo Bars, in the 14th Edith Adams Cookbook.

The search for evidence about the origin the bar also involved digging into some of the more common alternative names. Jean Paré, creator of the Company's Coming cookbooks, claimed the bars were originally called smog bars, and were from Alberta (Schultz \& Paré, 2006); the first recipe in the Vancouver Sun uses a name that is very similar. However an extensive search of Albertan cookbooks of the period turned up no reference to smog bars or fog bars of any kind. A wide range of names for the confection was found: Mrs. Ruby Polych of Drumheller called them Victoria Specials (Salvation Army, 1957); Mrs. Harold Payne of Nova Scotia called them Mabel's Squares (Upper Gloucester District Women's Institute, 1954); and in 1977 in an article in the Winnipeg Free Press, they are called the New York Slice, the only reference we found to this once-popular alternative (Larson, 1977). After searching 48 books drawn from archives in British Columbia and online, as well as gathered from local collections in Nanaimo, no reference to a Nanaimo bar or a similar recipe was found that predates 1952.

The newspaper search was more successful. It was found that no recipe for chocolate fridge cake had been published in the Vancouver Sun before 1953, nor any recipe for a Nanaimo bar or similar dessert. On the other hand, however, two recipes were found for what is the bottom layer of the bar. On April 18, 1947, Mrs. Lois Light of Vancouver submitted a Chocolate Quickie Square, which she suggested be frosted with peppermint butter icing (Vancouver Sun, 1947), and on February 21, 1948, Jean Haines of Wildwood submitted a recipe for Unbaked Chocolate Cake that she claims is from New Zealand (Vancouver Sun, 1948). This recipe was reproduced in the 12th Edith Adams Prize cookbook; it is worth noting that Nanaimo and Wildwood are both mill towns located opposite each other across the Strait of Georgia. If we then consider that the first recipe in the Sun for Nanaimo bars calls the middle layer a special icing rather than a filling, it becomes likely that the women of the hospital auxiliary created the Nanaimo bar by adapting the earlier cake recipe, inventing a new frosting, and capping the dessert with chocolate. Though not impossible, it is doubtful that a recipe from before 1947 will ever be found. Nanaimo bars seem to have been developed in Nanaimo, by combining an existing recipe with a new icing. Credit for the creation can be shared among the women of the Nanaimo Hospital auxiliary. However, the naming of the bar appears to have been done by the Edith Adams column in the Vancouver Sun, perhaps because of the cookbook in which the bar recipe first appears, or because of the source of many of the submitted recipes.

\section{Nanaimo bar as a populux dainty}

Though the early history of the Nanaimo bar is still someone cloudy, it is not a mystery as to how they fit into the foodways of the time. The bar can be classed as a dainty, a small sweet treat 
served at home or at public events such as church suppers, as it fits the model of these sweet, hand-held treats. Inness (2001, p.57) describes dainties as "frothy and cloudlike,” but extremely rich. These squares exploded in popularity after World War II, though as Diane Tye (2010) notes in her exceptional book, Baking as Biography, they were all rather similar. She discusses how dainties and baking in general was a status symbol in her mother's social circle, an attitude echoed by my own mother. The ability to entertain was expected, and the foods made were often fancy and extremely time consuming. A move towards using ready-made ingredients was more about status than time saving. Nanaimo bars, already costly due to their high butter and sugar content, required several purchased premade goods, and required time and care to make.

My own mother commented that these sweet treats were time wasting, a product of the free labour available in a society that excluded women from the workplace. Cusack (2004, p. 135) notes that "cuisines are not just innocent concoctions but reflect the dominant ideologies of the societies in which they emerge". Food became, as Bessière (1998) notes it often is, a class marker. Foods such as the Nanaimo bar also draw on faith in the processing industry and capitalism in general; Warren Belasco (2006) describes the foods of this period as populux; it was a period of optimism and faith in science and capitalism, where foods highlighted as easy because they included brand name goods (Tye, 2010) displaced earlier pioneer recipes.

\section{The road to a food of locality}

Many foods from the 1950s are no longer served. As noted by Gitelson (1992, p.1) "to describe suburban cuisine in the 1950s is to invoke images of hellish concoctions”. The Nanaimo bar's survival comes from the action of a few individuals, and from the attraction of the name. The Nanaimo bar is an excellent example of 'cultural proximity', a phenomenon in which sociocultural traditions are used to brand products (Renting et al., 2003); in this case, a bar made in a mill town is associated, through a name, with that region. As Adema (2009) notes, particular foods become iconic of specific places, the forces that inform this identification are often condensed or abstracted. So even though the exact origin of the bar was forgotten, the association remained intact (the hospital auxiliary link was only rediscovered in the 21st century).

The Nanaimo bar's popularity beyond Vancouver Island owes a lot to Susan Mendleson, co-founder of the Lazy Gourmet café and catering company in Vancouver. She sold the bars in the 1970s during college to pay her tuition (Kramer, 2011), and made the bars a cornerstone of her catering. Dorothy Duncan (2006) in Canadians at Table notes that The Lazy Gourmet in Vancouver claims to have been the first place to sell Nanaimo bars commercially. More importantly, Susan Mendleson was in charge of writing the cookbook for Expo '86, and she included three recipes for the bars. Very little has been written about Expo '86, and nothing about its food, but key events such as an Olympics (or an Expo) can greatly accelerate branding of a region's cuisine (Dinnie, 2004). Richman Kenneally (2008) explores this effect in her study of Montreal and Expo '67, and how a national cuisine was cobbled together for the fair. Expo '86 left similar imprints; Nanaimo began revitalizing its downtown, and the mayor held a contest to find the best Nanaimo bar recipe. (Joyce Hardcastle won, with a recipe that is still given on the town website today.)

After Expo '86, the Nanaimo bar spread rapidly as a Canadian treat; it can be found at Starbucks during the Christmas season, and is sold in sheets at Costco. BC Ferries still sells the bars, and Nanaimo began to embrace the bar as a potential tourist draw. The Nanaimo bar became a food of locality: a food that is deeply linked with a place, either through component ingredients 
or through association (in this case the latter). Susan Musgrave (2009) describes this effect as 'locationism': the Nanaimo bar evokes Nanaimo. In an examination of later cookbooks, after Expo '86 the bar almost always appears under the name Nanaimo Bar, rather than a variation.

\section{The Nanaimo bar trail}

Foods change over time. As Fabio Parasecoli (2008, p.10) remarks, foods are "the objects of ongoing negotiations within the communities that produced them, and the larger bodies of which those communities are a part”. In a world where smaller resource cities often find themselves marginalized, Nanaimo now positions itself online as a retirement hub, and the provisioning centre for the mid-island (Nanaimo News Bulletin, 2013). As Zukin (2010) has noted in her work on gentrification and globalization, food plays a role akin to art in the new era of urban culture. It has been noted that globalization is a matter not only of the emergence of a single homogenous 'world culture,' but equally of an increased preoccupation with local culture (Askegaard \& Kjeldgaard, 2007). In cases where there is no obvious food grown or processed in the region, whatever food of locality is on hand has to do; when Nanaimo looked to food to draw tourists, there was really only one food of locality available.

One popular way to achieve place branding through food is through a tasting trail, which draws the moneyed traveler into multiple transactions within a region. Hashimoto \& Telfer (2006) note the popularity of such trails; they have emerged as an important food tourism experience (Nexus \& Urban, 2003), even in what Ilbery \& Kneafsey (2000) call 'placeless foodscapes', without deeply engrained food culture. For the last few years Nanaimo has put together a suggested tasting trail that features over twenty variations on the classic bars. Minnoz restaurant offers a cheesecake version, Modern Café slings a Nanaimo bar martini, and Two Chefs Affair presents an ice cream version of the classic. There are gluten free versions and raw

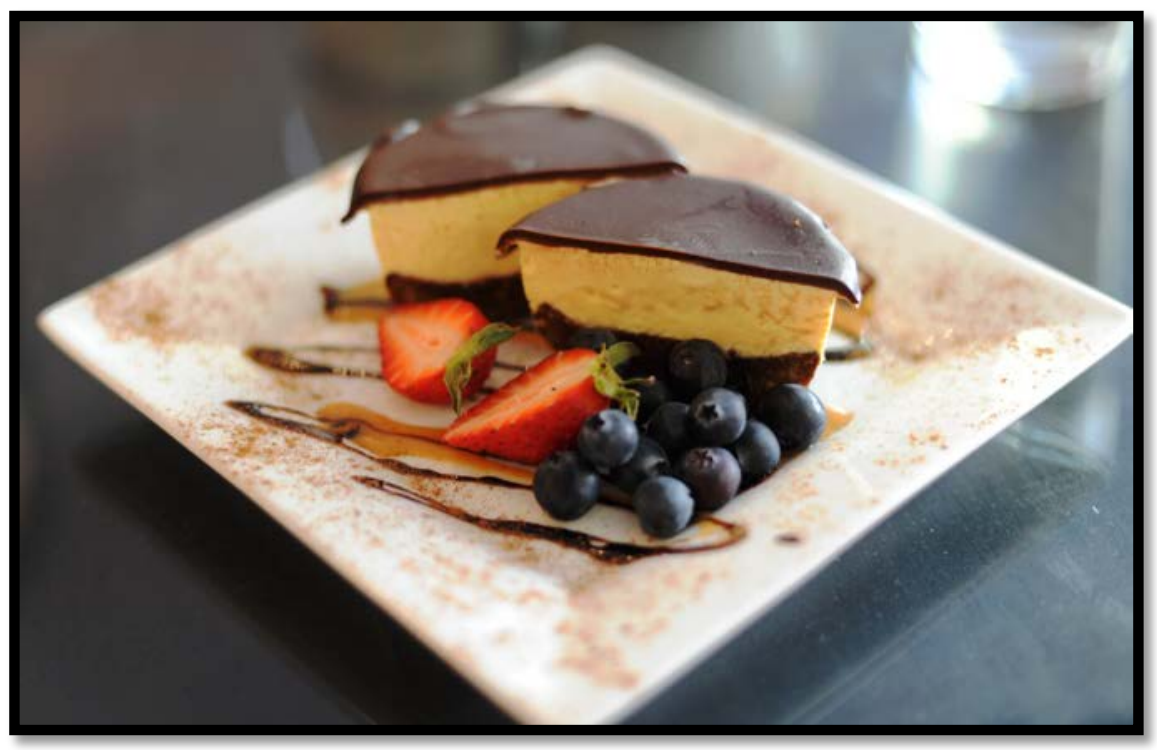
food versions, and of course a deep-fried version as well. Island Farms sells a popular ice cream version of the bar throughout the region. As one probably shouldn't eat more than one Nanaimo bar at a time, the trail can test even the most dedicated foodie, but it is no less calorie-laden than Ontario's two competing butter tart trails (Giovannetti, 2013).

Figure 2: Nanaimo bar Ice Cream Bar 


\section{Concluding thoughts}

The Nanaimo bar's exact origins remain mysterious, but the real innovation that happened in Nanaimo was most likely the invention of the custard frosting. The Vancouver Sun recipe for the bar's base suggests an origin for the confection, and dates the bar's inception as occurring in Nanaimo in the late 1940s. Though the Nanaimo bar doesn't fit well with current Canadian food trends, it reveals a rich hidden culinary history. Once a dainty served at home by a blue-collar middle class, the bar serves a place-making role in contemporary Nanaimo, even if it isn't an ideal food for a tasting trail due to its sweetness and calorie content. That the Nanaimo bar remains popular is testament to the power of sugar and nostalgia; during the course of this research many people related tales of childhood or of life in mid-twentieth-century mill towns. As Gibson (2007, p.15) notes, “food is a signifier of belonging, cultural identity, and home”. Though a new generation of Canadians is more likely to associate the bar with Costco than with a church supper, the taste lives on.

\section{Acknowledgements}

Archival research for this project was conducted in part by Shea Wind, a recent graduate of the University of the Fraser Valley. This research was funded in part by the Social Science and Humanities Research Council of Canada, and in part by the University of the Fraser Valley Research office.

\section{References}

Adema, P. (2009). Garlic Capital of the World: Gilroy, Garlic, and the Making of a Festive Foodscape. Jackson: University Press of Mississippi.

Askegaard, S., \& Kjeldgaard, D. (2007). Here there and everywhere: Place branding and gastronomical globalization in a macro-marketing perspective. Journal of Macromarketing, 27(2), 138-147.

Belasco, W. (2006). Meals to come: A History of the Future of Food. Berkeley and Los Angeles: University of California Press.

Bessière, J. (1998). Traditional food and cuisine as tourist attractions in rural areas. European Society for Rural Sociology, 38(1), 21-34.

CakeSpy. (2011, March 27th). Foodbuzz 24x24: Nanaimo Bar Extravaganza Retrieved from http://www.cakespy.com/blog/2011/3/27/foodbuzz-24x24-nanaimo-barextravaganza.html

Cusack, I. (2004). Equatorial Guinea's national cuisine is simple and tasty: Cuisine and the making of national culture. Arizona Journal of Hispanic Cultural Studies, 8, 131-148. 
Dinnie, K. (2004). Place branding: Overview of an emerging literature. Place Branding, 1(1), 106-110.

Driver, E. (2009). Regional differences in the Canadian daily meal? Cookbooks answer the question. In N. Cooke (Ed.), What's to Eat: Entrees in Canadian Food History (pp. 197212). Montreal: McGill-Queens University Press.

Driver, E. (2005). The Edith Adams Omnibus. Vancouver: Whitecap Books.

Duncan, D. (2006). Canadians at Table: A Culinary History of Canada. Toronto: Dundurn Press.

Duncan, D. (2003). Nothing more Comforting: Canada's Heritage Foods. Toronto: Dundurn Press.

Gertz, C. (1993). The Interpretation of Cultures. London: Fontana Press.

Gibson, S. (2007). Food mobility: Traveling, dwelling, and eating cultures. Space \& Culture, 10(1), 4-21.

Gitelson, J. (1992). Populox: the suburban cuisine of the 1950s. Journal of American Culture, 15(3), 73-78.

Giovannetti, J. (2013, July 5th). The rural Ontario battle over butter tarts. The Globe and Mail Retrieved from http://www.theglobeandmail.com/news/national/the-rural-ontario-battleover-butter-tarts/article13049446/

Hashimoto, A., \& Telfer, D. (2006). Selling Canadian culinary tourism: Branding the global and the regional product. Tourism Geographies, 8(1), 31-55.

Holtzman, J. D. (2006). Food and memory. Annual Review of Anthropology, 35, 361-378.

Hlutchy, P. (2003). Taste of the true north. Maclean's, 116(26/27), 67-72.

Ilbery, B., \& Kneafsey, M. (1999). Niche markets and regional specialty food products in Europe: Towards a research agenda. Environment and Planning A, 31, 2207-2222.

Inness, S. (2001). Dinner roles: American women and culinary culture. Iowa City: University of Iowa Press.

Jacobs, H. (2009). Structural Elements in Canadian Cuisine. Cuizine: The Journal of Canadian Food Culture, 2(1).

Johnston, J., \& Baumann, S. (2010). Foodies: Democracy and Distinction in the Gourmet Foodscape. New York: Routledge. 
Kowalchuk, K. (2013). Community cookbooks in the prairies. Cuizine: The Journal of Canadian Food Culture, 4(1).

Kramer, L. (2011, January 6). Susan Mendelson: Culinary legend. The Canadian Jewish News. Retrieved from http://www.cjnews.com/node/86989

Larson, E. (1977, April 30). The kitchen hot line. Winnipeg free press, 25.

Musgrave, S. (2009). Taste of Place, Place of Taste: Mapping Alimentary Authenticity through Marché Jean Talon (Master's Thesis). Concordia University, Montreal, QC.

Nanaimo News Bulletin. (2013). Gateway to Commerce in Nanaimo Retrieved from http://www.nanaimobulletin.com/eeditions/

National Post. (2006, June 30). Democracy never tasted so delicious. Retrieved from http://www.canada.com/nationalpost/news/story.html?id=c84dc36d-ade6-4595-931b$\underline{62 \mathrm{faf0773bb0}}$

Nexus, C., \& Urban, E. (2003). Twin Rivers Farm-food and Wine Trail: A success story. Bairnsdale: East Gippsland Shire Council.

Newman, L. (2012). Neige et citrouille: Marché Atwater and seasonality. Cuizine: The Journal of Canadian Food Culture, 3(2).

Parasecoli, F. (2008). Bite me: Food in Popular Culture. Oxford: Berg.

Rayburn, A. (2001). Naming Canada: Stories about Canadian Place Names. Toronto: University of Toronto Press.

Renting, H., Marsden, T., \& Banks, J. (2003). Understanding alternative food networks: Exploring the role of short food supply chains in rural development. Environment and Planning A, 35(3), 393-411.

Richman Kenneally, R. (2008). The cuisine of the tundra: Towards a Canadian food culture at Expo 67. Food, Culture, and Society, 11(3), 287-314.

Saberi, H. (2002). Whims and fancies of a trifle-lover, in Davidson, A. \& Saberi, H. The Wilder Shores of Gastronomy: Twenty Years of the Best Food Writing from the Journal Petits Propos Culinaires. New York: Ten Speed Press.

Salvation Army Drumheller Women's Corps. (1957). Cookbook. Drumheller: Salvation Army.

Schultz, J. \& Paré, J. (2006). Jean Paré: An Appetite for Life. Edmonton: Company's Coming Publishing. 
Smith, A. F. (2001). False memories: The invention of culinary fakelore and food fallacies. In E. Walker (Ed.), Food and the Memory: Proceedings of the Oxford Symposium on Food and Cookery (pp. 254-260). Totnes: Prospect Books.

Tucker, R. (2011, March 23). Exotic Canada: The great Canadian dessert, bar none. National Post. Retrieved from http://www.nationalpost.com/Exotic+Canada+great+Canadian+dessert+none/4491721/st ory.html

Tye, D. (2010). Baking as Biography: A Life Story in Recipes. Montreal: McGill-Queen's University Press.

Upper Gloucester District Women's Institute. (1954). The Country Woman's Favorite. St. Stephen's: Courier Press.

Vancouver Sun. (1953, April 11th). Reader's Prize Recipe: London Fog Bars, p 30.

Vancouver Sun. (1948, February 21st). Reader's Prize Recipe: Chocolate Quickie Square, p 20.

Vancouver Sun. (1947, April 18th). Reader's Prize Recipe: Unbaked Chocolate Cake, p 19.

Vehling, J. D. (1924). Cookery and Dining in Imperial Rome: A Bibliography, Critical Review and Translation of the Ancient Book Known as Apicius de Re Coquinaria. New York: Dover Publications.

Zeidler, M. (2013, December 31st). Dessert's origins unknown: Nanaimo calls it it's own. The Globe and Mail, Retrieved from: http://www.theglobeandmail.com/news/britishcolumbia/origins-unknown-nanaimo-calls-it-its-own/article16143830/

Zukin, S. (2010). Naked city: The Death and Life of Authentic Urban Places. Oxford: Oxford University Press. 